\section{Deliquescence in Urea and Methyl-ureas}

A communication in Nature from E. A. Werner ${ }^{1}$ directed attention to the deliquescence of urea and to the paucity of data concerning the vapour pressures of saturated solutions of urea and its derivatives, apart from the few observations of Adam and Metz ${ }^{2}$, and Edgar and Swan ${ }^{3}$. The accompanying figure gives vapour pressure curves for saturated solutions of urea, urea nitrate, N-methyl-urea, N.Nand N.N'-dimethyl-urea determined by the method described by Rowley ${ }^{4}$, and records the quaternary point for the system, urea, ice, saturated solution, vapour $\left(-11 \cdot 3^{\circ} \mathrm{C}\right.$.) for the first time.

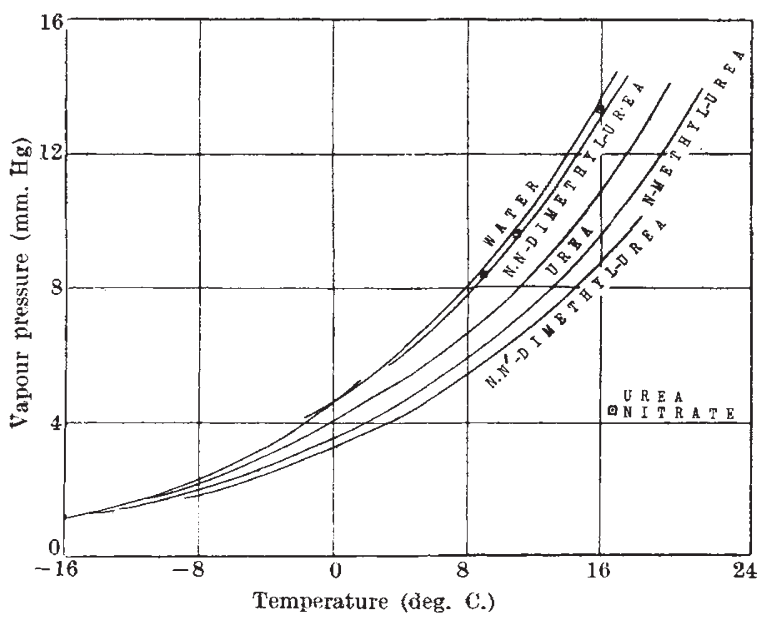

The vapour pressure curves confirm the observations of Werner upon the absorption of water by urea, etc., the vapour pressure of a saturated solution of urea being at all temperatures below $20^{\circ} \mathrm{C}$. less than $14 \mathrm{~mm}$. of mercury; consequently urea will show deliquescence except under conditions of unusually low humidity. The actual humidity required to cause deliquescence in these compounds, expressed as a percentage of the maximum vapour pressure of water at $18^{\circ} \mathrm{C}$, is :

\begin{tabular}{|c|c|c|c|}
\hline rea nitrate & . & $\theta$ & \\
\hline N.N-Dimethyl-urea & . & & \\
\hline Urea & .. & 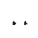 & \\
\hline $\begin{array}{l}\text { N-Methyl-urea } \\
N \text { N'-Dimethyl- }\end{array}$ & . & & \\
\hline
\end{tabular}

This shows N.N'-dimethyl-urea to be of the order of deliquescence of ammonium nitrate, urea and N-methyl-urea of sodium nitrate, and N.N-dimethylurea and urea nitrate of potassium nitrate.

The marked difference in the deliquescence of the methyl ureas is of interest on account of the various structures suggested for these compounds ${ }^{5}$.

Archibald Clow.

\section{Department of Chemistry, Marichal College, Aberdeen. May 20.}

\footnotetext{
1 Werner, NaTuRe, 139, 512 (1937).

2 Adam and Metz, Ind. and Eng. Chem., 21, 305 (1929).

s Edgar and Swan, J. Amer. Chem. Soc., 44, 570 (1922).

1 Rowley, J. Amer. Chem. Soc., 59, 621 (1937).

- Clow, Tran8. Faraday Soc, 33, 381 (1937).
}

\section{Examination of 'Egyptian Blue' by X-Ray Powder Photography}

X-RAY powder photography has been carried out upon various examples of the brilliant azure pigment known as 'Egyptian Blue'. It has been found as early as the Fourth Dynasty (2900-2250 B.c.) and its use became very widespread throughout the Roman Empire. By this method crude frits from Tel-el-Yehoudi (Egypt), Silchester (Berlsshire) and Woodeaton (Oxfordshire) have been shown to be of the same crystal form as a block already prepared for trading from Tel-el-Yehoudi, another in course of preparation from Armant (Egypt), and pale blue finely powdered pigment on pottery from Tel-elAmarna (Egypt), and on wall plaster frescoes from Woodeaton. A potsherd from Woodeaton contained the same finely powdered pigment and was obviously used as a palette. All these examples were shown to contain essentially copper, calcium, and silica, with varying small amounts of sodium. Laurie and others $^{1}$ had previously shown that examples of a similar blue from Egypt, Rome, Knossos (Crete), Syria, and Wroxeter (Shropshire) consisted essentially of a definite compound-CuO.CaO.4 $\mathrm{SiO}_{2}$, which assumes this brilliant azure only if formed between $800^{\circ} \mathrm{C}$. and $900^{\circ} \mathrm{C}$.; outside these limits the frit passes to a green glassy mass.

The crude frits were found in the form of agglomerates of small balls about $\frac{1}{2}$ in. in diameter, and this agrees remarkably well with Vitruvius's description (c. 24 B.c.) of the making of the pigment :

"Caeruleum was first made at Alexandria, then by Vestorius at Puteoli. . . . Sand and Natron (native Soda) are powdered together as fine as flour and Copper is grated by coarse files over the mixture. This is made into balls by rolling in the hands. The dried balls are then put into an earthen jar, which is put into a furnace. When the Copper and Sand have coalesced in the intense heat and the separate things have disappeared, the colour Caeruleum is made." The biconical form of the balls, resulting from rolling in the hands, is especially noticeable in the examples studied.

The application of X-ray powder photography to the study of this pigment provides a simple means of establishing its identity, even in the finely powdered form as it appears in paintings ; thus it was possible to identify copper aluminate, $\mathrm{CuAl}_{2} \mathrm{O}_{4}$, as being responsible for the blue colour on one pot from Tel-el-Amarna. It is hoped to extend the use of this method in the technological examination of antiquities.

\author{
Oriel College, \\ Oxford. \\ May 29. \\ 'Proc. Roy. Soc., A, 39, 418 ff (1913-14).
}

E. M. Jope.

\section{Attainment of the Upright Posture of Man}

IN his recent paper entitled "Fifty Years Ago", Sir Arthur Keith tells how, when in Siam in 1890 , he became impressed by the similarity in muscular and visceral adaptations shown by the hand-swinging gibbon and bipedal orthograde man. The gibbon suspends its body in an upright posture by hanging from its hands; man maintains his upright posture 